\title{
Fusarium verticillioides Migration in Attached and Detached Sweet Corn Ears
}

\author{
I.E. Yates ${ }^{1}$ \\ Toxicology and Mycotoxin Research Unit, Richard B. Russell Agricultural Research Center, USDA/ARS, \\ P.O. Box 6477, Athens, GA 30604
}

Darrell Sparks ${ }^{2}$

Department of Horticulture University of Georgia, Athens, GA 30501

\begin{abstract}
AdDitional INDEX words. Zea mays, mycotoxins, selection gene, hygromycin resistance, reporter gene, B-glucuronidase, bioassay

Aвstract. Mycotoxins harmful to humans and other animals are produced in kernels of sweet corn (Zea mays L.) during colonization by the fungus F usarium verticillioides (Sacc.) Nirenberg. Experimentation is limited under field conditions, due to the seasonality of the organisms, to once each year in temperate climates and under greenhouse conditions by the number of plants that can be grown. The objective of this study was to examine grocer ears (pistillate inflorescence) from retail stores as an alternative source for experimental material to use in bioassays to study this important food safety problem. Fusarium verticillioides migration was compared in sweet corn ears from a local grocery store and from greenhouse and field plants. Ears were inoculated with a $F$. verticillioides transformant tagged with a selection gene encoding resistance to hygromycin, a fungicidal antibiotic, and with a reporter gene encoding for $B$-glucuronidase, an enzyme detectable by histochemical staining. Screening kernels for both genes ensures unequivocal identification of the source of subsequent mycelia. Fusarium verticillioides colonized sweet corn ears towards the ear apex and base from the inoculation site regardless of ear source, incubation protocol, or attachment of the ear to the plant or to the shuck (spathe) and silks (styles) to the ear. Thus, ears from retail grocers can serve as experimental material for analyzing sweet corn and $\boldsymbol{F}$. verticillioides interactions throughout the year.
\end{abstract}

The fungus Fusarium verticillioides has a wide host range and is found on many major food crops including sweet corn (Bacon and Nelson, 1994; Bacon and Williamson, 1992; Kommedahl and Windels, 1981). Decreased crop production may result from vegetative and reproductive tissues of the developing corn plant becoming infected by this organism causing severe diseases, commonly referred to as seed, root, stalk, and kernel rots (Kommedahl and Windels, 1981; Kommedahl et al., 1979; Leslie et al., 1990; Warren and Kommedahl, 1973). In addition, kernel infection may produce a class of mycotoxins known as fumonisins that cause health problems in humans and other animals (Marasas et al., 1984, 1981; Norred, 1993).

The corn/F. verticillioides relationship is complicated by the fungus existing within the corn plant as an endophyte, an interaction of benefit to plant growth in other members of the Poaceae (Clay, 1990; Rice et al., 1990). Previous studies indicate that seed borne $F$. verticillioides is not detrimental and may benefit plant performance and productivity in the growth chamber under controlled environmental conditions and in the field under ambient conditions existing in southern Georgia (Yates et al., 1997, 2005). The challenge lies in determining and controlling the factors that convert the symptomless endophytic relationship with potential benefits to plant growth into a disease and mycotoxin producing interaction.

Woloshuk and Shim (2000) highlighted the corn ear as the most important plant organ for solving the food safety problems related to mycotoxin production. Kernels are the plant tissue in which fumonisins are primarily synthesized and on which a significant portion of the world's food and feed supply for humans and animals is based (White and Carson, 1999; Woloshuk and

Received for publication 2 Mar. 2005. Accepted for publication 11 May 2005. We thank Donnie Maxey and Joyce Lambert for technical assistance.

'To whom reprint requests should be addressed. E-mail address: iyates@ saa. ars.usda.gov
Shim, 2000). Kernel tissue in the developing ear is much more susceptible to colonization than other tissues (Yates and Jaworski, 2000). Knowledge of the hazardous effects to human and animal health resulting from $F$. verticillioides-infected corn kernels has spurred efforts to develop controls preventing the harmful features of this association. Progress is hampered by readily available experimental materials.

Control methods are needed for the deleterious aspects of the relationship especially with regard to infection of corn kernels. The ultimate test of a potential control agent is under field conditions; however, corn is an annual crop in temperate climates so testing is restricted to once each year. Furthermore, disease may or may not occur depending on extenuating biotic and abiotic factors (Dowd, 2003; Munkvold, 2003). In order to determine the factors that impinge on this relationship and expedite development of control agents, methods are needed for assessing corn throughout the year.

Bioassays have been used over the past 20 to 30 years for diverse scientific purposes from designing human cancer treatments to developing plant pesticides (Vlietinck, 1999). The purpose of this study was to compare $F$. verticillioides migration in sweet corn ears obtained from a retail grocer with $F$. verticillioides migration on ears from plants grown in the field and the greenhouse. If interchangeable with ears attached to the plant, retail grocer ears could provide a year round supply of experimental material and serve as a semi-in vitro bioassay for studying abiotic and biotic factors impacting $F$. verticillioides infection in sweet corn ears.

\section{Materials and Methods}

SOURCE AND PREPARATION OF $\boldsymbol{F}$. VERTICILLIOIDES INOCULUM. A wild-type isolate of $F$. verticillioides designated RRC PAT was transformed to carry two foreign genes that facilitate detection of the precise location of the organism (Yates et al., 1999a). 
The vector used in the transformations was a plasmid identified as pHPG, a gift from W. Schäfer, Institut für Genbiologische Forschung Berlin GmbH, Berlin, Germany. Plasmid pHPG has a transcriptional fusion of the P1 promoter from Cochliobolus heterostrophus Drechsler (Turgeon et al., 1987) with the gusA reporter gene encoding ß-glucuronidase (GUS), an enzyme detectable by histochemical staining. Plasmid pHPG has a second transcriptional fusion of the $\mathrm{P} 1$ promoter with the $h p h$ selectable gene, encoding for resistance to hygromycin (hygr), a fungal antibiotic (Mönke and Schäfer, 1993). Escherichia coli, strain DH5 $\alpha$ (GIBCO-BRLCo., Rockville, Md.), was used for transformation and plasmid multiplication (Sambrook et al., 1989). Fusarium verticillioides PATg mimics the parental wild type for reaction of growth characteristics to various media (Yates et al., 1999a); production of the mycotoxin, fumonisin $\mathrm{B}_{1 ;}$ and suppression of growth and mycotoxin production by an unidentified species of the fungus Trichoderma Persoon Fr. (Yates et al., 1999b). Fusarium verticillioides PATg was ideally suited for our studies because this organism functions like the wild type and yet can be detected by growth on medium containing hygromycin and confirmed by histochemical staining. Conidia of PATg were stored at $5{ }^{\circ} \mathrm{C}$ on silica gel until cultured (Perkins, 1962).

Fusarium verticillioides PATg was prepared for experimentation following inoculation onto minimal medium containing $100 \mu \mathrm{g} \cdot \mathrm{mL}^{-1}$ hygromycin $\mathrm{B}(\mathrm{MMH})$ (Boehringer Mannheim Corp., Indianapolis) (Puhalla and Spieth, 1983). Cultures were incubated in the dark for $7 \mathrm{~d}$ at $25^{\circ} \mathrm{C}$. Conidia were collected by flooding the agar surface of a culture with $10 \mathrm{~mL}$ of sterile distilled water. Concentration of conidia was determined by hemacytometer counts and adjusted with sterile distilled water to $1.0 \times 10^{6}$ conidia/mL for ear inoculations.

SOURCE OF SWEET CORN. Ears were obtained from a local retail grocery store and from plants growing in the greenhouse and field. Hereafter, they are referred to as grocer, greenhouse, and field ears, respectively. Grocer ears labeled 'Super Queen' white sweet corn were distributed by Hugh H. Branch Inc., Pahokee, Fla., and were purchased at Bell's Grocery Store, Athens, Ga. Grocer ears with and without shucks and silks and silks were examined because ears with shucks and silks are not always available at grocery stores.

Greenhouse sweet corn was grown from seeds of 'Silver Queen'. Six seeds were planted in 8.3-L pots containing Professional Potting Soil (Conrad Fafard, Agawam, Md.). Following shoot emergence to $\approx 20 \mathrm{~cm}$, plants were thinned to three plants/pot. Plants were grown on a 12-h light/12-h dark cycle with supplemental lighting and maintained at $25 / 20^{\circ} \mathrm{C}$ day/night temperature.

Field sweet corn was grown from seeds of 'Silver Queen' in irrigated field plots with otherwise ambient conditions existing at the Univ. of Georgia Plant Sciences Farm, Watkinsville, Ga. Each plot consisted of two rows $7 \mathrm{~m}$ long, planted to 40 seeds/row and thinned to $\leq 20$ seedlings/row 1 month after planting. Plants were thinned to $\approx 30 \mathrm{~cm}$ apart to ensure subsequent plant growth was not biased by plant density. Two rows were planted between each plot and six rows, around the entire periphery of the field using 'Pioneer 3167 ' to prevent reactions among plots or outside sources. 'Pioneer 3167' is a fungal resistant hybrid (Pioneer HiBred International, 2005). Field-grown sweet corn was maintained by standard Georgia cultural practices (Lee, 1994).

Fusarium VERTICILLIOIDES PATg INOCULATION AND SAMPLing OF GROCER EARS WITHOUT INTACT SHUCKS AND SILKS. Grocer ears with shucks and silks removed were cut into three equal trans- verse sections to maximize experimental material and designated apical, mid, and basal. The apical section was inoculated in the second fully expanded kernel from the apex, the midsection in the center, and the basal section in the second fully expanded kernel from the base at the site of former shuck attachment (Fig. 1A). Inoculations were made by puncturing an individual kernel $\approx 5 \mathrm{~mm}$ deep and $2 \mathrm{~mm}$ wide with a \#11 surgical blade. A $5-\mu \mathrm{L}$ suspension containing $\approx 1 \times 10^{6} \mathrm{~F}$. verticillioides $\mathrm{PATg}$ conidia $/ \mathrm{mL}$ was dispensed into the punctured kernel using a new pipette tip for each site. Control ears were inoculated with sterile distilled water by the same method. The ear sections of four ears were placed into a single plastic bag and incubated at $25^{\circ} \mathrm{C}$ and $50 \%$ relative humidity $(\mathrm{RH})$ in a growth chamber for $7 \mathrm{~d}$. For each experiment, there were four plastic bags for a total of 12 ears.

Kernels were collected from four sites on each of the three ear sections (apical, mid, and basal) to analyze for the presence of $F$. verticillioides PATg. Collection sites were designated numerically $\mathrm{K} 1$ through $\mathrm{K} 12$ proceeding from the ear apex to the base. $\mathrm{K} 1$ to $\mathrm{K} 4, \mathrm{~K} 5$ to $\mathrm{K} 8$, and $\mathrm{K} 9$ to $\mathrm{K} 12$ were from the apical, mid, and basal sections, respectively. $\mathrm{K} 1, \mathrm{~K} 6$, and $\mathrm{K} 11$ were from the inoculation sites. $\mathrm{K} 4, \mathrm{~K} 8$, and $\mathrm{K} 12$ were from the opposite side of the ear from the inoculation site. All other kernels were collected within the inoculated kernel row. K2 and K3 were $\approx 2$ and $4 \mathrm{~cm}$, respectively, distal to $\mathrm{K} 1$. $\mathrm{K} 5$ and $\mathrm{K} 7$ were $\approx 2 \mathrm{~cm}$ above and below, respectively, of inoculation site K6. K9 and K10 were $\approx 4$ and $2 \mathrm{~cm}$, respectively, above K11, the inoculation site on the basal section.

Fusarium Verticillioides PATg inOCUlation AND SAMPLING OF GROCER, GREENHOUSE, AND FIELD EARS WITH INTACT SHUCKS AND SILKs. Grocer, greenhouse, and field ears with intact shucks and silks were inoculated with a $1-\mathrm{mL}$ suspension containing $1 \times 10^{6}$ F. verticillioides PATg conidia/mL using a 5-mL syringe fitted with an 18-gauge needle. The needle was inserted into the shuck at the mid point of the total length of the ear until resistance was felt (Fig. 1B). The needle was withdrawn slowly while gently dispensing the conidial suspension. Control ears were inoculated with sterile distilled water by the same method. Greenhouse and field grown ears were inoculated at the dough stage to correspond to the stage of development of grocer ears.

Grocer ears were placed into a plastic bag and incubated at 25 ${ }^{\circ} \mathrm{C}$ and $50 \% \mathrm{RH}$ in a growth chamber for $7 \mathrm{~d}$. For each experiment, there were four plastic bags for a total of 12 ears. Grocer ears with shucks and silks were incubated the same as grocer ears without shucks and silks. Greenhouse and field grown ears were incubated directly on the plants under conditions described above for plant growth. Greenhouse grown ears were incubated for $14 \mathrm{~d}$ on the plant at $25 / 20{ }^{\circ} \mathrm{C}$ day/night temperature under a 12-h light/12-h dark cycle with supplemental lighting. Field-grown ears were incubated on the plant until kernel hardening, $\approx 40 \mathrm{~d}$ after inoculation, under ambient field conditions existing in Watkinsville, Ga., during the growing seasons of 2001 and 2002.

Kernels were collected from three sites on the ear designated apex, mid, and base to analyze for the presence of $F$. verticillioides PATg. The kernel position designated apex was $1 \mathrm{~cm}$ from the ear apex where silks formerly emerged from beneath the shuck, mid was the inoculation site, and base was $1 \mathrm{~cm}$ from the base of cob (rachis) at the former shuck attachment.

The experimental material and projected adaptation for future studies dictated the incubation times selected for each ear source in the current investigation. Preliminary examinations of kernel condition and $F$. verticillioides PATg after various incubation times were examined for grocer and greenhouse ears. Kernels on 
grocer ears, with and without shucks and silks, became spongy following incubation for $14 \mathrm{~d}$ in plastic bags at $25^{\circ} \mathrm{C}$. As a result, kernels could not be removed intact from the cob for analyses. Therefore, an incubation period of $7 \mathrm{~d}$ was selected for grocer ears. Preliminary examination indicated that $14 \mathrm{~d}$ were required for migration of $F$. verticillioides along the entire length of the ear under ambient greenhouse conditions. Thus, $14 \mathrm{~d}$ was selected as the incubation period for greenhouse ears. Field ears were collected at kernel hardening to provide a long incubation time for fungal development.

Fusarium Verticillioides PATg DisTRIBUTION IN EARS BASED ON ISOLATION OF HYGROMYCIN-RESISTANT MYCELIA FROM KERNELS. Grocer and greenhouse kernels were removed from apex, mid, and base position on the ear with a scalpel and placed directly onto petri dishes $(100 \times 15 \mathrm{~mm})$ containing $\mathrm{MMH}$ medium to assay for fungal isolates expressing the selection gene for hygr. Kernels from field grown ears were surface sterilized by submersion in $1 \%$ chloramine-T for 5 min followed by three rinses in sterile distilled water prior to placing in petri dishes containing $\mathrm{MMH}$ medium. Five kernels from a designated assay ear site were placed in each petri dish.

Petri dishes were incubated in darkness at $25{ }^{\circ} \mathrm{C}$ for $4 \mathrm{~d}$. The five kernels in each dish were examined for visible fungal growth and the number recorded (Fig. 2A). The percentage of kernels was calculated from which hygr mycelia were isolated. For example, if mycelia appeared on three of five kernels, the result would be expressed as $60 \%$ for hygr mycelia at the basal position for that ear.

Fusarium Verticillioides PATg Distribution IN EARS BASED ON HISTOCHEMICAL ANALYSES FOR GUS ACTIVITY IN HYGROMYCINRESISTANT MYCELIA. Sterile forceps were used to collect a $2-\mathrm{mm}^{2}$ mycelia sample from each kernel with fungal growth to assess GUS expression. Mycelia were placed in wells of a flat bottom, 96-well, gamma sterilized, tissue culture microplate (Rainin Instrument Co., Woburn, Mass.). Each well contained $100 \mu \mathrm{L}$ of histochemical staining solution consisting of $0.1 \mathrm{M}$ sodium phosphate buffer, pH 7.0; $0.1 \mathrm{mg} \cdot \mathrm{mL}^{-1}$ 5-bromo-4-chloro-3-indolyl-D-glucuronide (X-gluc); $0.5 \mathrm{~mm}$ each potassium ferri- and ferrocyanide and 10 mM EDTA (Stomp, 1992) (Fig. 2B). Plates were covered with 25.4- $\mu \mathrm{m}$-thick (1 mil) transparent, polyester pressure sensitive film (Falcon 3073; Becton Dickinson and Co., Oxnard, Calif.) to prevent evaporation of staining solution. Samples were incubated in the dark at $27^{\circ} \mathrm{C}$, and staining assessed at $48 \mathrm{~h}$. Mycelia were examined microscopically for blue stained hyphae as the reporter for F. verticillioides PATg (Fig. 2C). Percentage of GUS positive mycelia was calculated from the number of kernels from which

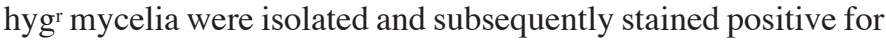
GUS expression. GUS expression would be expressed as $66 \%$ if hyg $^{\mathrm{r}}$ mycelia were isolated from three of the five kernels from a given position on the ear and only two of three mycelia samples tested positive for GUS.

EXPERIMENTAL REPLICATIONS AND DATA ANALYSIS. Experiments were set up in a completely randomized design for ears from all sources, grocer (with and without shucks and silks), greenhouse, and field ears. A treatment unit for the grocer, greenhouse, and field ears were those ears contained within a single plastic bag, pot, or plot, respectively. All ears within a treatment unit received the same inoculum. The inoculum was either water or $F$. verticillioides PATg. There were three plastic bags each with four grocery ears, four pots each with three plants bearing greenhouse ears, and four plots each with ten plants bearing field ears. Thus, 12, 12 , and 40 ears were examined for each experiment involving grocer, greenhouse, and field ears, respectively. More field ears were examined than from other sources as the abiotic and biotic conditions in the field would be expected to be more variable than in either the greenhouse or growth chamber.

Five kernels were removed at each sampling site on each ear and placed in a petri dish resulting in 70, 70, and 200 kernels analyzed for grocer, greenhouse and field ears, respectively, for each experiment. Experiments were repeated two times. The percentage of kernels with mycelia growth was calculated for each petri dish. The average was determined for the ears within a treatment unit, then the treatment units within each experiment and data reported is the mean of two experiments.

Data were analyzed using a statistical package (Statgraphics Plus, version 5.1; Manngistics, Rockville, Md.). Field ears were not different between 2001 and 2002 for each site by the $t$ test. Thus, data presented in the results are based on the means of the two years. Means of experiments were subjected to comparison by analysis of variance and separation by Fisher's least significant difference $(P \leq 0.05)$.

\section{Results}

FUSARIUM VERTICILLIOIDES DISTRIBUTION IN GROCER EARS WITHOUT INTACT SHUCKS AND SILKS. Macroscopic mycelial growth was visible following inoculation with $F$. verticillioides, but not with water, on grocer ears without shucks and silks that had been sectioned into three portions (Fig. 1A). Fungal mycelia were visible only at inoculation sites and not on kernels distant to the inoculation. Genetic evidence for the distribution of F. verticillioides PATg on sections of grocer ears was obtained by isolation of mycelia from kernels cultured on MMH medium indicating the expression of the selection gene coding for hygr (Table 1). Wild-type isolates of $F$. verticillioides, as well as other fungi, will not grow on $\mathrm{MMH}$ medium containing the antibiotic hygromycin. Further confirmation was obtained by mycelia staining blue on histochemical analysis for expression of the reporter gene coding for GUS (Table 1).

Kernel sites were compared within a given genetic trait for isolation of hygr mycelia, which subsequently stained positive for GUS. Isolation of hygr resistant mycelia was highest from kernels at inoculation sites $(\mathrm{K} 1, \mathrm{~K} 6$, and $\mathrm{K} 11)$, regardless of ear section (Table 1). Hyg ${ }^{r}$ resistant mycelia were isolated from only a few kernels basipetal (K2 and K3) to the inoculation site (K1) of the apical ear section and acropetal (K10 and K9) to the inoculation site (K11) of the basal ear section. In contrast, hygr-resistant mycelia were isolated from many kernels in the mid-ear section positioned in both acropetal (K5) and basipetal (K7) directions relative to the inoculation site (K 6). Hygr resistant mycelia were isolated from kernels on the side of the ear opposite the inoculation site (K4, K8, and K12) in all ear three sections.

GUS expression of mycelia isolated from the apical and basal sections was limited to the point of inoculation (K1 and K11). Mycelia tested positive for GUS expression that were isolated from kernels both acropetal (K5) and basipetal (K7) to the inoculation site in the mid ear section. No evidence of GUS expression was obtained for mycelia isolated from kernels on the side of the ear opposite the inoculation (K4, K8, and $\mathrm{K} 12$ ), regardless of the ear section (apical, mid, and basal).

Fusarium VERTICILlioides PATg DISTRIBUTION COMPARED AMONG GROCER, GREENHOUSE, AND FIELD EARS WITH INTACT SHUCKS AND SILKS BASED ON MACROSCOPIC MYCELIAL GROWTH. VISUal evidence of fungal growth differed among grocer, greenhouse, 
Table 1. Expression of the genes encoding for hygromycin resistance (hygr) and B-glucuronidase (GUS) in sweet corn grocer ears without shucks and silks, sectioned into three portions, following inoculation with Fusarium verticillioides PATg, a genetic transformant of the wild-type fungus, $F$. verticillioides PAT.

\begin{tabular}{|c|c|c|c|}
\hline \multirow[b]{2}{*}{ Ear section } & \multirow[b]{2}{*}{$\begin{array}{c}\text { Kernel } \\
\text { site }^{z}\end{array}$} & \multicolumn{2}{|c|}{ Gene expression $(\%)^{y}$} \\
\hline & & $\begin{array}{l}\text { Hygromycin } \\
\text { resistance }\end{array}$ & $\beta$-glucuronidase \\
\hline \multirow[t]{4}{*}{$\overline{\text { Apica1 }}$} & 1 & $83 a b$ & $70 \mathrm{a}$ \\
\hline & 2 & $9 d$ & $0 \mathrm{~b}$ \\
\hline & 3 & $9 d$ & $0 \mathrm{~b}$ \\
\hline & 4 & $9 d$ & $0 \mathrm{~b}$ \\
\hline \multirow[t]{4}{*}{ Mid } & 5 & $50 \mathrm{bcd}$ & $88 \mathrm{a}$ \\
\hline & 6 & $92 \mathrm{ab}$ & $75 \mathrm{a}$ \\
\hline & 7 & $58 \mathrm{bc}$ & $70 \mathrm{a}$ \\
\hline & 8 & $34 \mathrm{~cd}$ & $0 \mathrm{~b}$ \\
\hline \multirow[t]{4}{*}{ Basal } & 9 & $9 \mathrm{~d}$ & $0 \mathrm{~b}$ \\
\hline & 10 & $9 d$ & $0 \mathrm{~b}$ \\
\hline & 11 & $100 \mathrm{a}$ & $67 \mathrm{a}$ \\
\hline & 12 & $34 \mathrm{~cd}$ & $0 \mathrm{~b}$ \\
\hline
\end{tabular}

zInoculated kernel sites at 1, 6, and 11 on the apical, mid and basal sections, respectively, as designated in figure 1. Kernels collected within the inoculated kernel row. Kernels sites 2 and 3 were $\approx 2$ and $4 \mathrm{~cm}$ distal to the inoculation site, respectively, on the apical ear section; 5 and 7 were $\approx 2 \mathrm{~cm}$ above and below the inoculation site, respectively, on the mid ear section; and 9 and 10 were $\approx 4$ and $2 \mathrm{~cm}$ above the inoculation site, respectively, on the basal ear section. Kernels collected from 4, 8 , and 12 were from the opposite side of the ear of the inoculation site on the apical, mid, and basal section, respectively.

yEach value is reported as percent kernels from which mycelia were isolated and assayed positive for the expression of the genes encoding hygr and GUS and represents the mean of two experiments. Each experiment consisted of three replications of four ears per replication and five kernels at each site (i.e., 70 kernels for each site for each experiment). Different letters following means in a column indicate a significant difference among kernels. Statistical analysis based on analysis of variance and mean separation by Fisher's least significant difference $(P \leq 0.05)$.

and field ears with intact shucks and silks following inoculation with $F$. verticillioides PATg (Fig. 3). Fungal mycelia were visible only at the inoculation site and not other portions of the ear for both grocer and greenhouse ears treated with intact shucks and silks (Fig. $3 \mathrm{~A}$ and B). Furthermore, visible kernel damage was restricted to the inoculation site and a few kernels surrounding the site. In contrast, field-grown ears had more extensive fungal growth and kernel damage, especially from the middle of the ear to the base (Fig. 3C).

Fusarium VERTICILlioides PATg Distribution COMPARED AMONG GROCER, GREENHOUSE, AND FIELD EARS WITH INTACT SHUCKS AND SILKS BASED ON ISOLATION OF HYG ${ }^{R}$ MYCELIA FROM KERNELS. Expression of the selection gene encoding hygr was compared among kernel positions (apex, mid, and base) from ears within a given source (grocer, greenhouse, and field) following inoculation with water and $F$. verticillioides PATg (Table 2). The percent kernels from which hygrmycelia were isolated was unaffected by ear position for water-inoculated ears regardless of ear source. Hygr-resistant mycelia were absent on kernels cultured from water-inoculated grocer and greenhouse ears and present on only a low percentage $(4 \%)$ of kernels cultured from water inoculated field ears.

Kernels tested positive for hygr expression at acropetal and basipetal positions relative to inoculation sites of $F$. verticillioides PATg-inoculated ears from all three sources. Isolation of hygr mycelia from kernels was affected by position (apex, mid, and
Table 2. Hygromycin resistant (hygr) mycelia isolated from kernels of sweet corn ears with intact shucks and silks following inoculation with either water or Fusarium verticillioides PATg (Fv), a genetic transformant of the wild-type fungus, $F$. verticillioides PAT.

\begin{tabular}{lcrcr}
\hline \multirow{2}{*}{ Inoculum } & Kernel & \multicolumn{3}{c}{ Hygromycin resistance expression $(\%)^{\mathrm{z}}$} \\
\cline { 3 - 5 } & position & Grocer & Greenhouse & Field \\
\hline Water & Apex & $0 \mathrm{a} 1$ & $0 \mathrm{a} 1$ & $4 \mathrm{a} 1$ \\
& Mid & $0 \mathrm{a} 1$ & $0 \mathrm{a} 1$ & $4 \mathrm{a} 1$ \\
& Base & $0 \mathrm{a} 1$ & $0 \mathrm{a} 1$ & $4 \mathrm{a} 1$ \\
$\mathrm{FV}$ & Apex & $93 \mathrm{~b} 1$ & $56 \mathrm{~b} 2$ & $49 \mathrm{~b} 2$ \\
& Mid & $100 \mathrm{~b} 1$ & $94 \mathrm{c} 2$ & $89 \mathrm{~d} 2$ \\
& Base & $93 \mathrm{~b} 1$ & $70 \mathrm{~b} 2$ & $79 \mathrm{c} 2$
\end{tabular}

${ }^{2}$ Each value is expressed in percent kernels with mycelia testing positive for hygr and represents the mean of two experiments. Different letters following means in a column indicate a significant difference among kernels based on inoculum and/or position on the ear. Different numbers following means in a row indicate a significant difference among ear sources (grocer, greenhouse, and field). Statistical analysis based on Fisher's least significant difference procedure $(P \leq 0.05)$.

Table 3. B-glucuronidase (GUS) active mycelia isolated from kernels of from sweet corn ears with intact shucks and silks following inoculation with either water or Fusarium verticillioides $\mathrm{PATg}(\mathrm{Fv})$, a genetic transformant of the wild-type fungus, $F$. verticillioides PAT.

\begin{tabular}{lcccc}
\hline \multirow{2}{*}{ Inoculum } & Kernel & \multicolumn{3}{c}{ B-glucuronidase active mycelia $(\%)^{\mathrm{z}}$} \\
\cline { 3 - 5 } Water & position & Grocer & Greenhouse & Field \\
\hline \multirow{5}{*}{ Fv } & Mid & $0 \mathrm{a}$ & $0 \mathrm{a}$ & $0 \mathrm{a}$ \\
& Base & $0 \mathrm{a}$ & $0 \mathrm{a}$ & $0 \mathrm{a}$ \\
& Apex & $73 \mathrm{~b} 1$ & $0 \mathrm{a}$ & $0 \mathrm{a}$ \\
& Mid & $100 \mathrm{c} 1$ & $97 \mathrm{~b} 2$ & $94 \mathrm{~b} 2$ \\
& Base & $72 \mathrm{~b} 1$ & $91 \mathrm{~b} 2$ & $98 \mathrm{~b} 1$ \\
& & &
\end{tabular}

${ }^{\mathrm{z}}$ Each value is expressed in percent kernels with mycelia positive for GUS and represents the mean of two experiments. Different letters following means in a column indicate a significant difference among kernels based on inoculum and/or position on the ear. Different numbers following means in a row indicate a significant difference among ear sources (grocer, greenhouse, and field). Statistical analysis based on Fisher's least significant difference procedure $(P \leq 0.05)$.

base) for greenhouse and field ears, but was unaffected for grocer ears (Table 2). Mycelia percentage was higher at the mid kernel position, the inoculation site, than the apex or the base for both greenhouse and field ears for kernels from which hygr mycelia were isolated. The percentage of kernels did not differ between the apex and base kernels from greenhouse ears, but field ears had a higher percentage of hygr mycelia isolated from kernels from the base than the apex.

Expression of the selection gene encoding hygr was compared among the ear sources (grocer, greenhouse, and field) inoculated with water and $F$. verticillioides PATg within a given kernel position (apex, mid, and base) (Table 2). Differences within a given kernel position were not significant among ear sources for the isolation of hygr mycelia from water-inoculated ears, but was significant for $F$. verticillioides-inoculated ears. The percentage of kernels with hygr mycelia was higher in grocer, than greenhouse or field ears, regardless of kernel position (apex, mid, or base). The mid-ear kernel position was the inoculation site with the least difference among ears of different sources (grocer, greenhouse, and field ears) with an average of $94 \%$ for all sources. However, grocer ears had more kernels testing positive for the presence of hygr mycelia at both the apex and base than either greenhouse or field ears. 


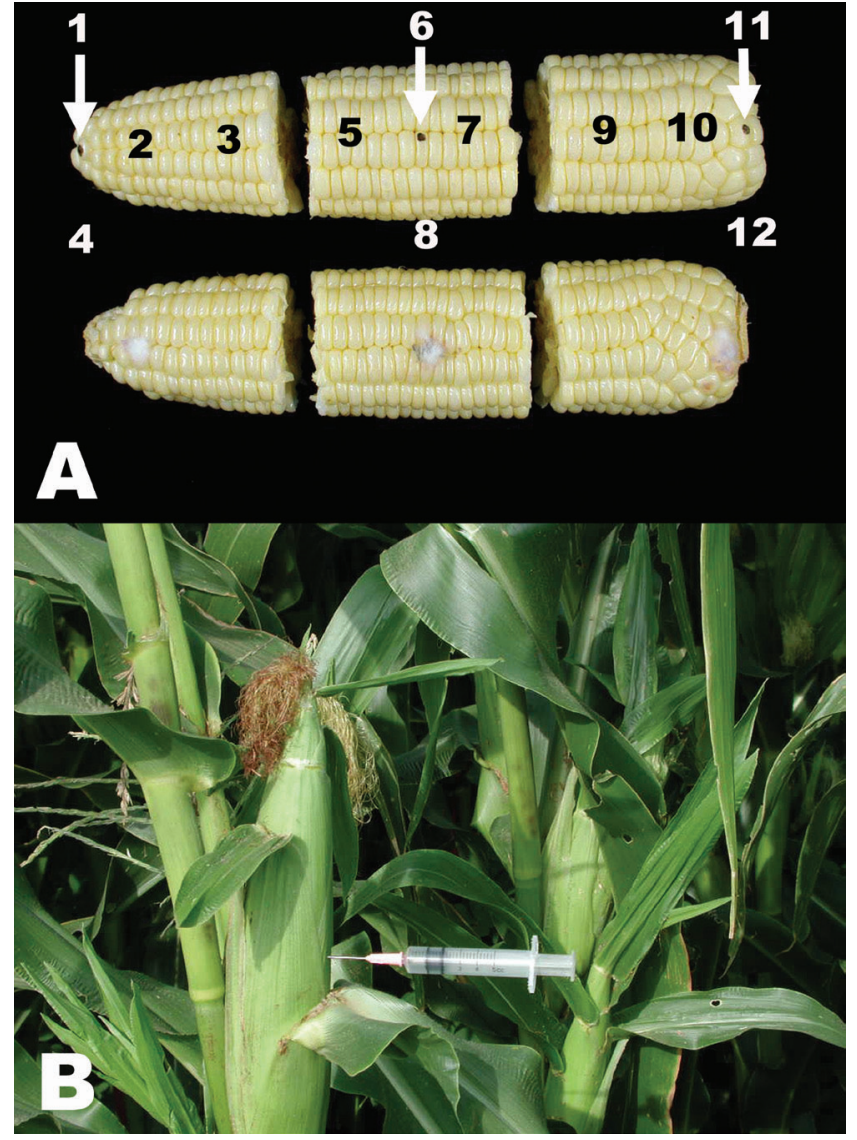

Fig. 1. Ear inoculations. (A) Sweet corn grocer ears without shucks and silks were cut into three equal sections and designated apical, mid, and basal. Black dots and arrows indicated sites inoculated with Fusarium verticillioides PATg, a genetic transformant of the wild-type fungus, F. verticillioides PATg. The apical section was inoculated in the second fully expanded kernel from the apex; the mid section, in the center; and the basal section, in the second fully expanded kernel from the base. The top ear was inoculated with water and the bottom ear with $F$. verticillioides PATg as evidenced by mycelia growth at the site inoculated. Numbers designate sites at which kernels were collected for examination of hygromycin-resistant mycelia with $\beta$-glucuronidase activity. Collections 1, 6, and 11 were at inoculation sites; 2 and 3 were $\approx 2$ and $4 \mathrm{~cm}$ distant of the inoculation site on the apical ear section; 5 and 7 were $\approx 2 \mathrm{~cm}$ above and below the inoculation site; 9 and 10 were $\approx 4$ and $2 \mathrm{~cm}$ above the inoculation site on the basal section; 4,8 , and 12 were from the opposite side of the ear from the inoculation sites on the apical, mid, and basal ear sections. (B) Sweet corn ears on field grown plants were inoculated with either $F$. verticillioides PATg or water at the midpoint of the total length of the ear using a needle and syringe inserted though the shuck. The same method was used to inoculate grocer and greenhouse ears with intact shucks and silks.

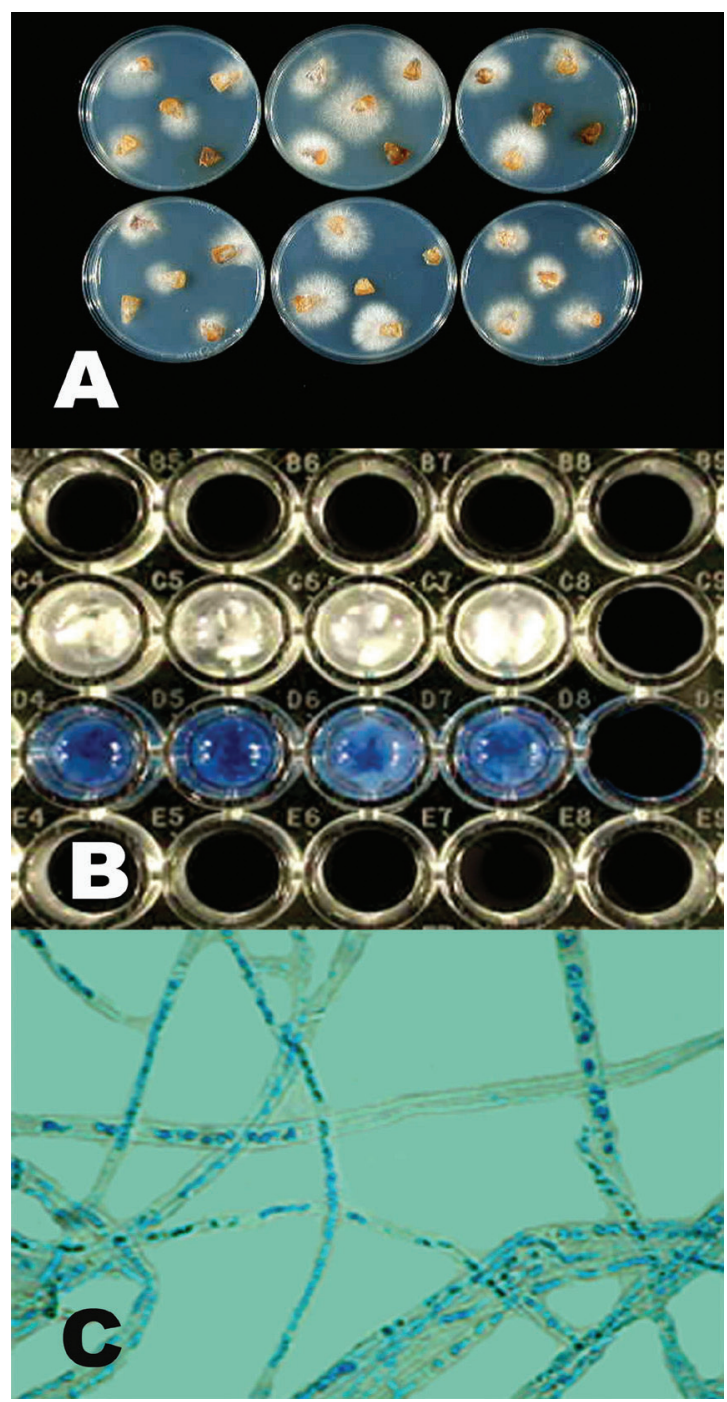

Fig. 2. (Above) Assessment of the presence of Fusarium verticillioides PATg, a genetic transformant of the wild-type fungus, F. verticillioides PATg. (A) Mycelia cultured from kernels incubated on minimal medium containing hygromycin indicate the expression of the selection gene encoding for hygromycin resistance. (B) Mycelia suspended in $100 \mu \mathrm{L}$ staining solution in the second and third row of wells of a microtitre plate. Wells appearing black are empty. The second row is white and the third row is blue indicating a negative and positive response, respectively, for the expression of the reporter gene responsible for synthesizing B-glucuronidase. (C) Microscopic examination verifies the blue stain is resident in the hyphae as the marker for $F$. verticillioides PATg.

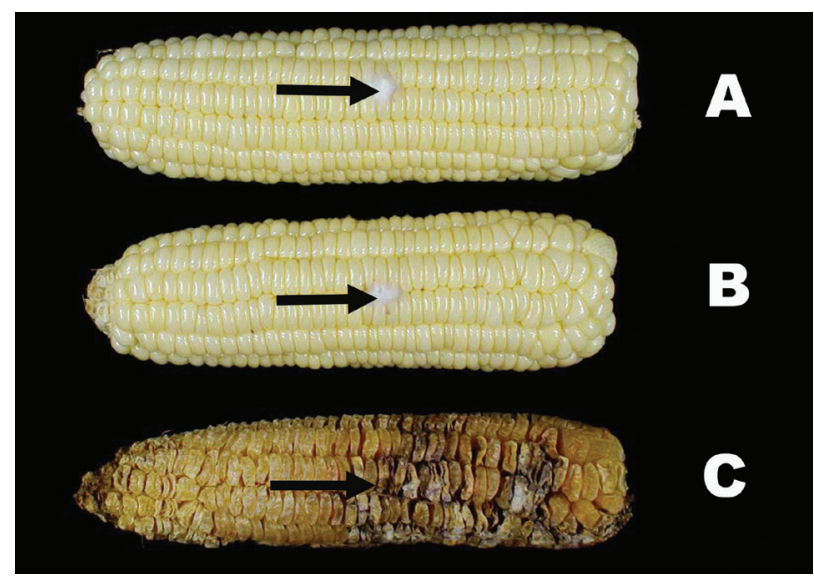

Fig. 3. (Right) Sweet corn ears with intact shucks and silks inoculated with Fusarium verticillioides PATg, a genetic transformant of the wild-type fungus, F. verticillioides PAT. Visual evidence of fungal mycelia was present only at the inoculation site of $(\mathbf{A})$ grocer and $(\mathbf{B})$ greenhouse ears; however, mycelia were evident throughout the length of $(\mathbf{C})$ field ears. Arrows designate location of mycelial growth. 
Fusarium Verticillioides PATg distribution COMPARED AMONG GROCER, GREENHOUSE, AND FIELD EARS WITH INTACT SHUCKS AND SILKS BASED ON HISTOCHEMICAL ANALYSES FOR GUS ACTIVITY IN HYGROMYCIN-RESISTANT MYCELIA. GUS expression was based on the percent kernels from which cultured mycelia stained blue. Field ears were the only source from which hygr mycelia were isolated following water-inoculation (Table 2), but none stained positive for GUS (Table 3). Percentage of kernels with blue-stained hyphae was different between water- and $F$. verticillioides PATg-inoculated ears regardless of source (grocer, greenhouse, or field).

Mycelia stained positive for GUS that were isolated from $F$. verticillioides PATg-inoculated ears, regardless of source. Staining was different among kernel positions on grocer ears, but not greenhouse or field ears. Among ear sources, staining was similar in the mid-kernel position with a range of $98 \%$ to $100 \%$. GUS expression in mycelia from greenhouse and field ears was higher in the apex and base kernel positions than in grocer ears.

\section{Discussion}

Importance of the current study lies in the development of a semi-in vitro bioassay for studying potential control methods for a critical food safety problem with global impact. The problem is created by the association of one of the world's major food crops, corn, with the fungus, $F$. verticillioides. For nearly a century, concern about the corn $/ F$. verticillioides relationship has been from the crop production aspect with this fungus being only one of many found in diseased parts of the corn plant (White and Carson, 1999). Interest catapulted in this plant/fungal relationship over the last two decades with the discovery that the corn $/ F$. verticillioides association results in the synthesis of mycotoxins, especially in corn kernels, that are deleterious to animal and human health (Kuldau and Yates, 2000). The health aspect of this interaction is not restricted to a particular geographical site. Mycotoxins produced during the corn $/ F$. verticillioides association have been reported in corn food products from around the globe (Shephard et al., 1996).

The bioassay described in the current research includes both the colonizer, F. verticillioides, and the colonized, corn ear, organisms. In vitro technology has been used for decades by scientists to study the impact compounds have on various organisms (Vlietinck, 1999). These systems usually involve only the colonizer. Techniques involving both organisms in a dual relationship would more accurately reflect the efficacy of potential control agents.

Migration of $F$. verticillioides was compared in sweet corn ears bought at a local grocer with those growing on plants in the field and greenhouse. Grocer ears with and without shucks and silks were examined because the impact of silks in kernel infections, even in field-grown corn ears, has been ambiguous (Munkvold et al., 1997). Early studies implicated an association of silks with the infection process (Koehler, 1942). In contrast, more current investigations designed to evaluate inoculation techniques that bypassed silks indicate silks may not be essential for infection (Bush et al., 2000; Clements et al., 2000). Grocer ears with and without silks were examined due to the conflict regarding the roles of silks in infection and to the possibility of grocer ears with intact shucks and silks being unavailable. Thus, investigation of $F$. verticillioides migration was required for grocer ears with and without silks to establish their utility for in vitro tests of potential biocontrol agents.

The bioassay incorporates not only the colonized plant organ, the corn ear, but also a genetically transformed isolate of $F$. verticillioides with two foreign genes for tracking its location. One gene confers hygr and fungi carrying the gene can be selected by growth on medium containing hygromycin. The second gene is responsible for the synthesis of GUS which can be detected by histochemical analyses. Other systems, such as vegetative compatibility of fungal isolates, have been used to track $F$. verticillioides in the corn plant (Leslie, 1993; Munkvold et al., 1997). Tracking expression of hygr and GUS minimizes time for analyses and provides a definitive characterization of the origin of fungal isolates following inoculation. However, analyzing for only one trait may produce inconclusive results. Leslie and Dickman (1991) implicated the presence of naturally occurring hy $\mathrm{g}^{\mathrm{r}}$ in the $F$. verticillioides gene pool. In the current study, hygr mycelia were visible following culture of a small percentage of kernels from field ears tested. Thus, monitoring for hygr mycelia alone does not appear to provide irrevocable evidence of the presence of a particular $F$. verticillioides isolate. Not only does screening for hygr alone produce dubious results, but screening corn tissues for GUS alone has problems (Yates and Jaworski, 2000). Control, noninoculated corn tissues, as well as tissues inoculated with the $F$. verticillioides isolate PATg carrying the gusA gene, stained blue in histochemical assays for GUS activity. Hu et al. (1990) reported previously an intrinsic GUS-like activity for the corn fruit. The most efficient, definitive, reliable, and repeatable method for screening for $F$. verticillioides isolate PATg is to assess corn tissues first for activity of the selection gene and then for the reporter gene. Mycelia grown from plant tissue incubated on $\mathrm{MMH}$ media provide evidence for the activity of the gene encoding hygr and mycelia staining blue in histochemical assays, of the gene encoding for GUS.

Our study demonstrated inoculation sites had visible $F$. verticillioides mycelia that tested positive for genes carried by the transformed $F$. verticillioides on grocer ears with or without shucks and silks. F. verticillioides mycelia were visible on kernels at the inoculation site, but not kernels distant to the inoculation. However, mycelia were cultured from symptomless kernels distant to the inoculation site and then stained positive for GUS. Thus, grocer ears could be used to assess the influence of potential biocontrols both on the externally applied $F$. verticillioides, such as from insects, as well as the symptomless migration of the fungus in grocer ears with and without shucks and silks.

Grocer ears may need to be assessed as experimental tools for research objectives other than evaluating potential growth control agents for $F$. verticillioides. Fungal migration patterns on grocer, greenhouse and field ears did differ somewhat in the amount of infection at particular kernel sites, whether measuring hyg ${ }^{\mathrm{r}}$ or GUS. Usefulness of grocer ears may require validation with field ears for some studies, such as comparing the time-course of infection from the inoculated middle kernel with and without shucks and silks or characterization of corn genotypes with varying genetic backgrounds from different geographic regions.

In conclusion, we propose grocer ears could serve as a first line screening tool to expedite solutions pertaining to developing control methods for $F$. verticillioides to increase food safety. Grocer corn ears are available in ample quantities throughout the year, whereas greenhouse ears may be limited by numbers and field-grown ears by season. Furthermore, temperature can be optimized for rapid $F$. verticillioides migration, thereby reducing the time required for screening control agents. However, the final analyses of the efficacy of a potential control agent must be conducted under field conditions. 


\section{Literature Cited}

Bacon, C. and P.E. Nelson.1994. Fumonisin production in corn by toxigenic strains of Fusarium moniliforme and Fusarium proliferatum. J. Food Protection 57:514-521.

Bacon, C.W. and J.W. Williamson. 1992. Interactions of Fusarium moniliforme, its metabolites and bacteria with corn. Mycopathologia 117:65-71.

Bush, B.J., M.L. Carson, M.A. Cubeta, W.M. Hagler, and G.A. Payne. 2000. Tracking Fusarium verticillioides infection and fumonisin accumulation in North Carolina corn. Aflatoxin/Fumonisin Wrkshp. 2000 p. 52. (Abstr.).

Clements, M.J., D.G. White, and C.M. Maragos. 2000. Evaluation of inoculation methods for Fusarium ear rot of corn. Aflatoxin/Fumonisin Wrkshp. 2000. p. 53. (Abstr.).

Clay, K.1990. Fungal endophytes of grasses. Annu. Rev. Ecol. Syst. 21:275-297.

Dowd, P.F. 2003. Insect management to facilitate preharvest mycotoxin management. J. Toxicol. Toxin Rev. 22:327-350.

Hu, C., P.P. Chee, R.H. Chesney, J.H. Zhou, P.D. Miller, and W.T. O'Brien. 1990. Intrinsic GUS-like activities in seed plants. Plant Cell Rpt. 9:1-5.

Kommedahl, T. and C.E. Windels. 1981. Root-, stalk-, and ear-infecting Fusarium species on corn in the USA, p. 94-103. In: P.E. Nelson, T.A. Toussoun, and R.J. Cook (eds.). Fusarium: Disease, biology, and taxonomy. Penn. State Univ. Press, University Park.

Kommedahl, T., C.E. Windels, and R.E. Stucker. 1979. Occurrence of Fusarium spp. in roots and stalks of symptomless corn plants during the growing season. Phytopathology 69:961-966.

Koehler, B. 1942. Natural mode of entrance of fungi into corn ears and some symptoms that indicate infection. J. Agr. Res. 8:421-442.

Kuldau, G. and I.E. Yates. 2000. Evidence for endophytic Fusarium, p. 85-117. In: C.W. Bacon and J.F. White (eds.). Microbial endophytes. Marcel Decker, New York.

Lee, R.D. 1994. Irrigated corn production in Georgia. Bul. 891:282-S291. Coop. Ext. Serv., Univ. Ga. College Agr. Environ. Sci., Athens.

Leslie, J.F. 1993. Fungal vegetative compatibility. Annu. Rev. Phytopathol. 31:127-150.

Leslie, J.F. and M. B. Dickman.1991. Fate of DNA encoding hygromycin resistance after meiosis in transformed strains of Gibberella fujikuroi (Fusarium moniliforme). Appl. Environ. Microbiol. 57:1423-1429

Leslie, J.F., C.A.S. Pearson, P.E. Nelson, and T.A. Toussoun. 1990. Fusarium spp. from corn, sorghum, and soybean fields in the central and eastern United States. Phytopathology 80:343-350.

Marasas, W.F.O., P.E. Nelson, and T.A. Toussoun. 1984. Toxigenic Fusarium species. Pennsylvania State Univ. Press, University Park.

Marasas, W.F.O., F.C. Wehner, S.K. van Rensburg, and D.J. van Schlkwyk. 1981. Mycoflora of corn produced in human esophageal cancer areas in Transkei. Phytopathology 71:792-796.

Mönke, E. and W. Schäfer. 1993. Transient and stable gene expression in the fungal maize pathogen Cochliobolus heterostrophus after transformation with the $\beta$-glucuronidase (GUS) gene. Mol. Gen. Genet. 241:73-80.

Munkvold, G.P. 2003. Cultural and genetic approaches to managing mycotoxins in maize. Annu. Rev. Phytopathol. 41:99-116.

Munkvold, G.P., D.C. McGee, and W.M. Carlton. 1997. Importance of different pathways for maize kernel infection by Fusarium moniliforme. Phytopathology 87:209-217.

Norred, W.P. 1993. Fumonisins-Mycotoxins produced by Fusarium moniliforme. J. Toxicol. Environ. Health 38:309-328.

Perkins, D.D. 1962. Preservation of Neurospora stock cultures with anhydrous silica gel. Can. J. Microbiol. 8:591.

Pioneer Hi-Bred International, Inc. 2005. Product information guide corn detail. Pioneer Brand corn hybrid, 3167. 12 May 2005. <http://www. pioneer.com/products/ProductDetail.asp?ProductCode $=3167 \& S A=$ IB\&language_cd $=01 \&$ ProductLine $=010 \&$ use $=\mathrm{G} \&$ ChartType $=\mathrm{PRO}$ DUCTS>

Puhalla, J.E. and P.T. Spieth. 1983. Heterokaryosis in Fusarium moniliforme. Expt. Mycol. 7:328-335.

Rice, J.S., B.W. Pinkerton, W.C. Stringer, and D.J. Unersander. 1990. Seed production in tall fescue as affected by a fungal endophyte. Crop Sci. 30:1303-1305.

Sambrook, J., E.F. Fritsch, and T. Maniatis. 1989. Molecular cloning: A laboratory manual. Cold Spring Harbor Laboratory Press, Cold Spring Harbor, N.Y.

Shephard, G.S., P.G. Thiel, S. Stockenström, and E.W. Sydenham. 1996. Worldwide survey of fumonisin contamination of corn and corn-based products. J. Assn. Offic. Anal. Chemists Intl. 79:671-687.

Stomp, A.M. 1992. Histochemical localization of B-glucuronidase, p. 103-113. In: S.R. Gallagher (ed.). GUS protocols: Using the GUS gene as a reporter of gene expression. Academic, San Diego.

Turgeon, B.G., R.C. Garber, and O.C. Yoder. 1987. Development of a fungal transformation system based on selection of sequences with promoter activity. Mol. Cellular Biol. 7:3297-3305.

Vlietinck, A.J. 1999. Screening methods for detection and evaluation of biological activities of plant preparations, p. 42-52. In: L. Bohlin and J.G. Bruhn (eds.). Bioassay methods in natural product research and drug development. Kluwer, Boston.

Warren, J.L. and T. Kommedahl. 1973. Prevalence and pathogenicity to corn of Fusarium species from corn roots, rhizosphere, residues, and soil. Phytopathology 63:1288-1290.

White, D.G. and A.M. Carson. 1999. History of corn, p. 1-2. In: D.G. White (ed.). Compendium of corn diseases. APS Press, St. Paul, Minn.

Woloshuk, C.P. and W-B. Shim. 2000. Regulation of fumonisin biosynthesis: The corn kernel holds the key. Aflatoxin/Fumonisin Wkshp. 2000. p. 48. (Abstr.).

Yates, I.E, C.W. Bacon, and D.M. Hinton. 1997. Effects of endophytic infection by Fusarium moniliforme on corn growth and cellular morphology. Plant Dis. 81:723-728.

Yates, I.E. and A.J. Jaworski. 2000. Differential growth of Fusarium moniliforme relative to tissues from 'Silver Queen', a sweet maize. Can. J. Bot. 78: 472-480.

Yates, I.E., K.L. Hiett, D.R. Kapczynski, W. Smart, A.E. Glenn, D.M. Hinton, C.W. Bacon, R. Meinersmann, S. Liu, and A.J. Jaworski. 1999a. GUS transformation of the maize fungal endophyte Fusarium moniliforme. Mycol. Res. 103:129-136.

Yates, I.E., F. Meredith, W. Smart, C.W. Bacon, and A.J. Jaworski. 1999 b. Trichoderma viride suppresses fumonisin $\mathrm{B}_{1}$ production by Fusarium moniliforme. J. Food Prot. 62:1326-1332.

Yates, I.E., N.W. Widstrom, C.W. Bacon, A. Glenn, D.M. Hinton, D. Sparks, and A.J. Jaworski. 2005. Field performance of maize grown from $\mathrm{Fu}$ sarium verticillioides-inoculated seed. Mycopathologia 159:63-73. 